УДК 37.013.75+57.05+612:796

DOI: $10.24144 / 2524-0609.2021 .49 .111-115$

\author{
Мусіснко Олена Володимирівна \\ кандидат біологічних наук, доцент \\ кафедра фізичного виховання, спорту і здоров'я \\ Львівський національний університет ветеринарної медицини та біотехнологій імені С.З.Гжицького \\ м. Львів, Україна \\ musiyenko1976@gmail.com \\ http://orcid.org/0000-0002-0153-8262
}

\title{
Чопик Роман Володимирович
}

кандидат педагогічних наук, доцент кафедра теорії та методики фізичного виховання

Дрогобицький державний педагогічний університет імені Івана Франка м.Дрогобич, Україна rchpopyk@ukr.net

http://orcid.org/0000-0002-1749-775X

\section{Кізло Наталія Богданівна} доцент

кафедра спортивних дисциплін та методики їх викладання Дрогобицький державний педагогічний університет імені Івана Франка м.Дрогобич, Україна natalyakizlo61@gmail.com

http://orcid.org/0000-0003-3301-7311

\section{ВИЗНАЧЕННЯ АКТИВНОСТІ РЕФЛЕКСОГЕННИХ ЗОН ТІЛА ПІД ЧАС ВИКОНАННЯ СТАТИЧНОЇ ВПРАВИ ХАТХА-ЙОГИ (ДГАНУРАСАНА)}

Анотація. Метою дослідження - встановити можливість використання методики вивчення впливу фізичних вправ на організм засобами акупунктурної діагностики за методикою Й.Накатані на прикладі статичної вправи, яка виконується подібно до Дганурасани (поза лука у Хатха-Йозі). Обстежено десять студенток. Вимірювання поводили до виконання вправи, під час та після виконання вправи через 6 хвилин. Результати досліджень показали суттєві зміни показників електричної активності у репрезентативних точках меридіанів тіла. Встановлено підвищення електричної активності у меридіанах тіла людини, які відповідають за функції дихальної, серцево-судинної систем, нирок та наднирників, жовчного міхура, тонкого і товстого кишечника, селезінки, підшлункової залози, печінки і сечового міхура, та їі зниження у меридіані шлунку. Обрана методика акупунктурної діагностики дозволяє визначати електричну активність меридіанів тіла людини під час виконання статичних фізичних вправ. Можна запропонувати використання цієї методики дослідження впливу фізичних вправ на організм людини поряд з іншими загальноприйнятими науковими методами.

Ключові слова: фізичне виховання; статична вправа; методика акупункурної діагностики.

Вступ. Механізми акупунктури залишаються погано вивченими, але зазвичай вважається, що вимірюванням електропровідності різних меридіанів тіла людини можна отримати дані, які показують енергії меридіана. Такі неінвазивні методи використовують для стимулювання точок акупунктури на меридіанах (тепло, електрика, магніти і лазери). У пошуках інформації про хвильові характеристики меридіанів ми проаналізували досить значний масив даних літератури [7; 8-26].

Аналіз останніх досліджень і публікацій. За даними літератури про метод Ryodoraku усі біологічно активні точки тіла людини поєднані у меридіани. Кожен меридіан несе інформацію про функціональний стан внутрішніх органів [16; 20]. Меридіани містять канали, які з'єднують поверхню тіла з внутрішніми структурами. Первинні меридіани (усього 12) розташовані в тілі симетрично 3 двох боків. Меридіанні канали з'єднують лівий і правий меридіани [15-18]. Мережа меридіанних каналів знаходиться в м'яких сполучних тканинах. У працях традиційної китайської медицини детально описано нормальні фізіологічні функції, патологічні стани, можливі механізми захворювань, передачу сигналів від органів чуття $[13 ; 19 ; 25]$. Механізми акупунктури вивчені недостатньо, існує потреба підтвердження їх ефективності для організму людини 3 допомогою наукових методів. Вимірювання електричної провідності
(ЕП) різних меридіанів дозволить отримати показники, які потім можна інтерпретувати [16]. Вимірявши електричний опір шкіри, Й.Накатані у 1950 році виявив лінії підвищеної електропровідності, які співпали $з$ традиційними меридіанами тіла людини. Ці лінії він назвав «шляхом струму» або «Ryodoraku» $[15 ; 18]$. Вимірювання ЕП від кожної активної точки меридіану $є$ дуже трудомісткий процес через їхню велику кількість. Й.Накатані визначив репрезентативні точки кожного з меридіанів, які виявляють середні значення енергії меридіану. За показниками ЕП від репрезентативних точок можна зробити висновок про стан органів, які пов'язані з певним меридіаном. Така методика $є$ інформативною що до діагностики захворювань [17].

Проведення пробних досліджень дозволило нам підтвердити нашу гіпотезу про доцільність використання методики Ryodoraku як засобу термінової інформації для визначення впливу фізичних вправ на організм людини.

Мета дослідження. 1. Обгрунтувати можливість використання даної методики дослідження для визначення впливу фізичних вправ на організм людини. 2. Дослідити зміни електричної провідності репрезентативних точок організму людини до, під час та після виконання вправи.

Методи дослідження: було застосовано методи аналізу та узагальнення спеціальної літератури 3 
проблематики акупунктурної діагностики; методика дослідження Ryodoraku за Й.Накатані [16] за допомогою приладу, аналогічного описаному в літературі $[3 ; 15 ; 22]$ (рис. 1$)$.

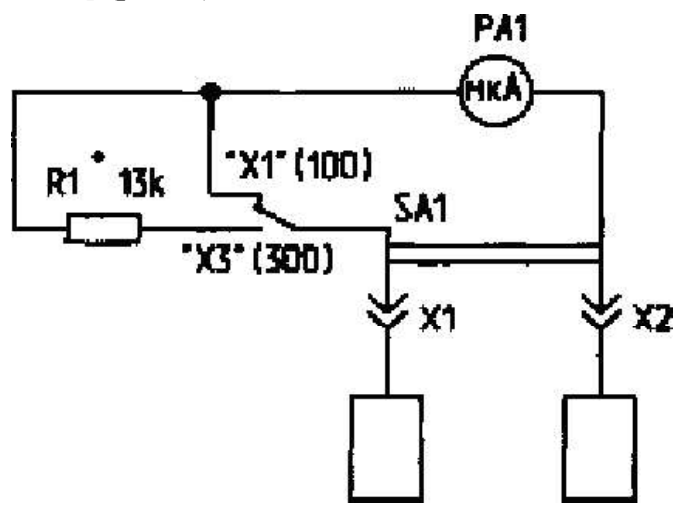

Рис. 1. Схема приладу для вимірювання електричної провідності репрезентативних точок меридіанів тіла людини [3]

У наших дослідженнях проведено вимірювання електричного струму в репрезентативних біологічно активних точках дванадцяти головних меридіанів: легенів (P), перикарда (MC), серця (C), лімфатичної та імунної систем (TR), тонкого (IG) і товстого (GI) кишківників, селезінки та підшлункової залози (RP), печінки (F), нирок (R), сечового (V) і жовчного (VB) міхурів та шлунка (E) з метою визначення можливості вивчення впливу фізичних вправ на організм методами акупунктурної діагностики. В дослідженнях взяли участь десять студенток ДДПУ ім. I. Франка
18-20 років, які досконало володіли технікою виконання статичних вправ Хатха-Йоги і практикували їх не менше одного року. Досліджену вправу усі студентки виконували технічно вірно.

Виклад основного матеріалу. Під час проведення досліджень впливу виконання статичної вправи (рис. 2) на організм людини утримання пози тривало 10 хв, відпочинок після її виконання - 6 хв. Відпочинок проводили в положенні лежачи на спині 3 максимальним розслабленням усіх м'язів (Шававсана або «мертва поза» Хатха-Йоги). Вправу виконували на заняттях з фізичного виховання під керівництвом викладачів кафедри за нашою програмою.

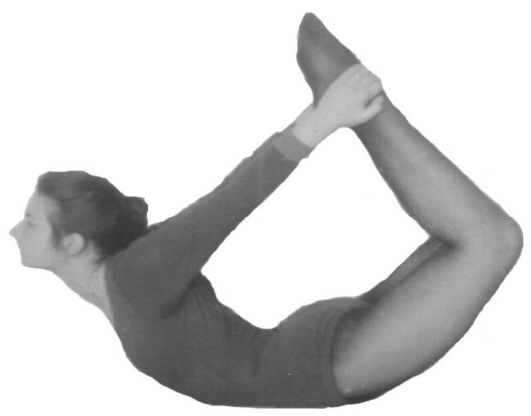

Рис.2. Статична вправа (Дганурасана)

Аналіз динаміки показників акупунктурної діагностики засвідчив (табл. 1, рис. 3): ця вправа більшою чи меншою мірою впливає на всі органи, які досліджували.

Таблиця 1.

Динаміка показників акупунктурної діагностики (мкА) до, під час та після виконання Дганурасани

\begin{tabular}{|c|c|c|c|c|c|c|c|c|c|c|}
\hline \multirow{2}{*}{ Номер } & \multirow{2}{*}{ Показники } & \multicolumn{2}{|c|}{ До виконання } & \multicolumn{2}{|c|}{ Під час виконання } & \multicolumn{4}{|c|}{ Після виконання } \\
\cline { 3 - 10 } & & $\mathrm{X}$ & $\mathrm{m}$ & $\mathrm{X}$ & $\mathrm{m}$ & $\mathrm{P}_{1}$ & $\mathrm{X}$ & $\mathrm{m}$ & $\mathrm{P}_{2}$ & $\mathrm{P}_{3}$ \\
\hline 1 & $\mathrm{P}$ & 4,8 & 0,23 & 5,8 & 0,28 & $<0,01$ & 9,4 & 0,26 & $<0,001$ & $<0,001$ \\
\hline 2 & $\mathrm{Mc}$ & 4,4 & 0,36 & 5,75 & 0,28 & $<0,05$ & 6,95 & 0,36 & $<0,05$ & $<0,001$ \\
\hline 3 & $\mathrm{C}$ & 4,6 & 0,26 & 5,2 & 0,31 & $<0,01$ & 7,2 & 0,24 & $<0,001$ & $<0,001$ \\
\hline 4 & $\mathrm{IG}$ & 4,8 & 0,23 & 3,95 & 0,23 & $<0,05$ & 6,1 & 0,11 & $<0,01$ & $<0,05$ \\
\hline 5 & $\mathrm{TR}$ & 3,6 & 0,26 & 3,15 & 0,28 & $<0,05$ & 4,85 & 0,29 & $<0,01$ & $<0,01$ \\
\hline 6 & $\mathrm{GI}$ & 4,1 & 0,26 & 5,45 & 0,20 & $<0,01$ & 5,1 & 0,21 & $<0,05$ & $<0,01$ \\
\hline 7 & $\mathrm{RP}$ & 5,3 & 0,23 & 6,3 & 0,19 & $<0,001$ & 7,0 & 0,16 & $<0,05$ & $<0,001$ \\
\hline 8 & $\mathrm{~F}$ & 4,7 & 0,23 & 5,7 & 0,26 & $<0,01$ & 6,85 & 0,29 & $<0,01$ & $<0,01$ \\
\hline 9 & $\mathrm{R}$ & 4,6 & 0,26 & 4,1 & 0,25 & $<0,05$ & 7,55 & 0,16 & $<0,001$ & $<0,001$ \\
\hline 10 & $\mathrm{~V}$ & 4,9 & 0,17 & 4,15 & 0,21 & $<0,05$ & 4,4 & 0,18 & $<0,05$ & $<0,05$ \\
\hline 11 & $\mathrm{VB}$ & 5,0 & 0,20 & 4,5 & 0,23 & $<0,05$ & 5,7 & 0,23 & $<0,05$ & $<0,05$ \\
\hline 12 & $\mathrm{E}$ & 4,8 & 0,23 & 4,35 & 0,26 & $<0,05$ & 3,9 & 0,18 & $>0,05$ & $<0,01$ \\
\hline
\end{tabular}

Примітки:

P1 - достовірність розбіжностей між показниками до виконання і під час виконання пози. Р2 - достовірність розбіжностей між показниками під час виконання пози і після ії виконання; Р3 - достовірність розбіжностей до виконання пози і після ії виконання

У табл. 1 подано дані акупунктурної діагностики в 12 головних меридіанах: до, під час та після виконання Дганурасани. Так, у меридіані Р під час утримання пози показники ЕП достовірно зростають на $20,8 \%$ ( $<0,01)$, після виконання збільшуються на $62,0 \%(\mathrm{P}<0,01)$, що засвідчує значне активізуванння функціонування легенів. У меридіанах Мс і С зафіксовано теж поступове зростання показників ЕП. Після відпочинку вони стають більшими за вихідний рівень відповідно на 57,9\% та 56,5\% (P<0,001), що свідчить про посилення функцій серцево-судинної системи.

Показники ЕП у меридіані TR під час виконання

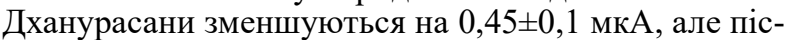

ля виконання суттєво зростають приблизно на 53,9\% $(\mathrm{P}<0,01)$, а порівняно 3 вихідним рівнем стають більшими на $34,7 \%(\mathrm{P}<0,01)$, що засвідчує активізування лімфатичної та імунної систем.

Аналогічні коливання показників ЕП зафіксовані у меридіані IG. Після виконання пози вони стають більшими на $27,1 \%(\mathrm{P}<0,01)$ від вихідного рівня, тобто Дханурасана сприяє посиленню функції тонкого кишечнику.

У меридіані GI показники ЕП зростають на $32,9 \%$ під час виконання пози, після ії виконання дещо зменшуються, проте залишаються достовірно більшими від вихідного рівня на 24,4\% ( $<20,01)$.

Поступове зростання показників ЕП зафіксо- 


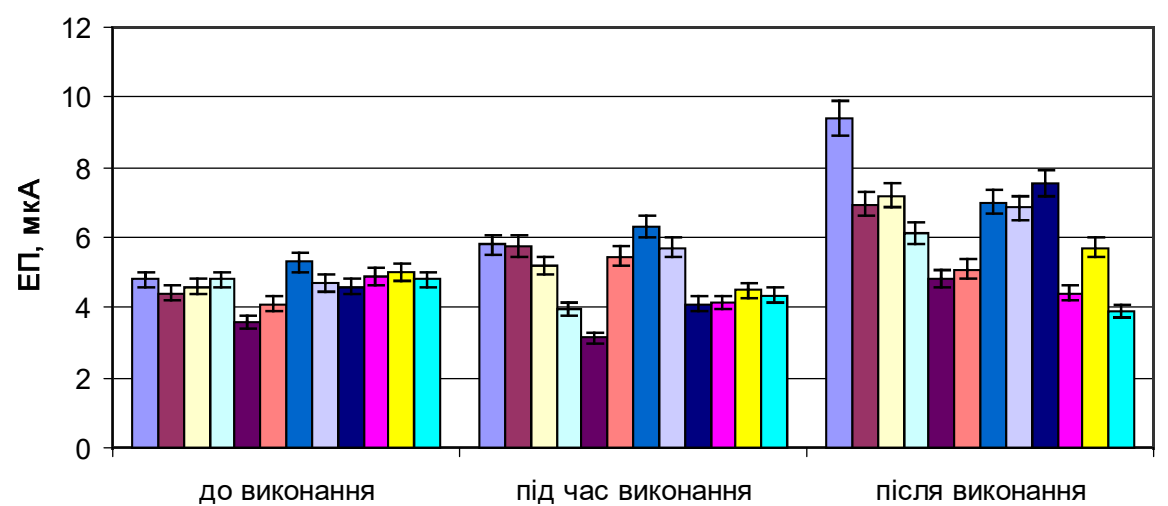

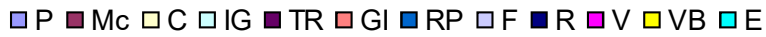

Рис.3. Діаграма показників акупунктурної діагностики (мкА) до, під час та після виконання вправи

Умовні позначення: меридіани легенів (P), перикарда (Mc), серця (C), лімфатичної та імунної систем (TR), тонкого (IG) і товстого (GI) кишківників, селезінки та підшлункової залози (RP), печінки (F), нирок (R), сечового (V) і жовчного (VB) міхурів та шлунка (E).

вано у меридіані RP. Під час виконання асани вони зростають на 18,9\%, після іiї виконання ще на 11,1\%. Загальний приріст показників ЕП становить 32,0\% $(\mathrm{P}<0,001)$, що засвідчує активізування селезінки та підшлункової залози.

У меридіані F відбувається аналогічна картина, що констатує поступове збудження функцій печінки. Після виконання вправи показники ЕП стають більшими від початкових даних на $45,7 \%(\mathrm{P}<0,01)$.

$\mathrm{V}$ меридіані $\mathrm{R}$ під час утримання пози показники ЕП зменшуються на $10,9 \%(\mathrm{P}<0,05)$, однак після відпочинку зростають на $3,45 \pm 0,1$ мкА, що становить $84,1 \%$, а порівняно з вихідним рівнем - $64,1 \%$ $(\mathrm{P}<0,001)$ приросту показників, і свідчить про значне стимулювання функції нирок.

Подібні зміни показників ЕП зафіксовані у меридіані VB. Під час утримання пози його показники трохи зменшуються, але після їі виконання достовірно зростають $(\mathrm{P}<0,05)$ і становлять рівень вищий від початкового на $14,0 \%$. Тобто виконання цієї асани сприяє посиленню функцій жовчного міхура.

У меридіані V показники ЕП під час виконання вправи зменшуються, після ії виконання зростають, але не досягають вихідного рівня на $10,3 \%(\mathrm{P}<0,05)$, що засвідчує зниження функції сечового міхура.

Показники ЕП у меридіані Е зменшуються під час виконання пози на 9,4\% (P<0,05), після ії виконання несуттєво зменшуються ще на $10,4 \%(\mathrm{P}>0,05)$, однак, порівняно 3 початковими даними, кінцеві результати достовірно нижчі на $18,7 \%(\mathrm{P}<0,01)$, що свідчить про пригнічувальну дію асани на функцію шлунку.

На нашу думку, такі зміни ЕП під час виконання статичної вправи Дганурасана відбуваються внаслідок зміни положення внутрішніх органів, зміною плину крові в них, а також зміною загального кровоплину внаслідок зворотнього ортостатичного положення тіла, що підтверджується думкою авторів $[1 ; 2 ; 5]$. Під час виконання Дганурасани відбувається перерозподіл крові з судин нижніх та верхніх кінцівок у тулуб і внутрішні органи, кровоплин стає більш інтенсивним у вісцеральних органах, також вісцеральні органи перебувають у стані стискання, що веде до змін у їхньому функціонуванні.

Окрім того, значна активізація функцій внутрішніх органів відбувається вже після припинення виконання вправи, коли внутрішні органи зі стану стискання переходять у стан спокою в положенні лежачи на спині.
Дана методика досліджень впливу фізичних вправ на організм є неінвазивною, не створює дискомфорту для обстежуваної людини, дозволяє швидко отримувати показники від репрезентативних точок, тобто можна рекомендувати ії використання для вивчення впливу фізичних навантажень на організм людини у різних вікових групах (від дитячого віку до старечого). Показники, які отримують з допомогою іiі використання, досить легко інтерпретувати, а відтак можна застосовувати ії для вивчення впливу різних фізичних вправ, в тому числі динамічних, на організм людини.

Методи акупунктурної діагностики дозволяють слідкувати за змінами в організмі в режимі реального часу, тобто дають термінову інформацію про стан органів в даний момент часу, що дуже корисно для тренерів і осіб, які займаються фізичною активністю, для розуміння стану організму під час тренувань і корекції фізичних навантажень.

Висновки. Використання методів акупунктурної діагностики у вивченні впливу фізичних вправ на організм дозволило нам встановити, що дана статична вправа (Дганурасана) виявляє вплив на електропровідність репрезентативних точок меридіанів тіла людини. Дослідженнями доведено, що виконання Дганурасани сприяє активізації функціонування багатьох органів та систем організму. Так, зростає функція серцево-судинної, лімфатичної та імунної систем, органів травлення, печінки, селезінки, підшлункової та щитоподібної залоз, сечового міхура. В той же час відбувається пригнічення функції шлунку. Активізуються функції нирок, жовчного міхура, легенів, перикарда та серця. Проведені дослідження дозволяють нам стверджувати, що використання даної методики досліджень є доцільним у вивченні впливу фізичних вправ на організм.

Перспективи подальших досліджень с вивчення впливу різних фізичних вправ на організм 3 використанням методів акупунктурної діагностики. Ці методи дозволять дослідити електричну провідність репрезентативних точок меридіанів тіла людини під час виконання інших асан Хатха-Йоги, що дозволить складати комплекси вправ та індивідуальні програми тренувань для потреб осіб, які займаються фізичною активністю 3 різних вікових груп. Крім того, $є$ перспектива вивчення інших фізичних вправ (наприклад, динамічних і статичних вправ східних гімнастик) у поєднанні з іншими загальноприйнятими методами дослідження. 


\section{Список використаної літератури}

1. Вишну-девананда С. Полная иллюстрированная книга йоги. Пер. с англ. Москва: Паритет - ИН Фолио, 1990. 206 с.

2. Джафаров М.А. Анатомо-топографические изменения некоторых внутренних органов при физических упражнениях. Автореф. дис. ... д-ра мед. наук. Москва, 1968. 42 с.

3. Индикатор энергии человека. Каталог радиолюбительских схем РЛ2-2000. http://www.irls.narod.ru/rlbt/med/med02.htm

4. Крапивина Е.А. Физические упражнения йогов. Москва: Знание. №3. 1991. 85 с.

5. Крапівіна К.О., Мусієнко О.В. Нетрадиційний підхід до традиційної фізичної культури: монографія. Львів, 2006.300 с.

6. Мачерет Е.Л., Самосюк И.З. Руководство по рефлексотерапии. Київ: ВШ, 1982. 301 с.

7. Мерсон М.А. Система риодораки как субъективный критерий оценки эффективности лечения иглорефлексотерапией. II Pесп. конф. молодых учёныхх-медиков: сб. материалов. Рига, 1985. С.129-130.

8. Табеева Д.М. Руководство по иглорефлексотерапии. Москва: Медицина, 1982. 560 с.

9. Buts'ka L.V. Analysis of obtained data after electropuncture diagnostics in sportsmen with different professional qualification. Lik. Sprava. 2006. № 5-6. P.43-49.

10.Fribus A.G. Electrophysiological studies by the method of measuring the transcutaneous electrical current with Nakatani tables in healthy men exposed in a thermal chamber. Vopr. Kurortol. Fizioter. Lech. Fiz. Kult. 1999. № 5. P.24-26.

11. Goldura N., Goția S. Incursion into bioelectromagnetism. Rev. Med. Chir. Soc. Med. Nat. Iasi. 2010. V.114, № 1. P.266-270.

12.Hyodo M.D. Ryodoraku treathment and objective approach to acupuncture. Osaka, 1975. $226 \mathrm{p}$.

13.Huang S-M, Chien L-Y, Chang C-C, Chen P-H, Tai CJ. Abnormal gastroscopy findings were related to lower meridian energy. Evidence-based Complementary and Alternative Medicine. 2011. URL: https://downloads.hindawi.com/journals/ ecam/2011/878391.pdf (дата звернення: 02.10.2012 р.)

14.Korkushko A.O, Lyshnevskiî S.A. Computerized acupuncture methods in the diagnosis of autonomic nervous system disturbances. Lik. Sprava. 2001. № 5-6. P.117-119.

15.Liu CZ, Chang YH. Channel medicine and meridian doctrine. Journal of Chinese Medical Association of Acupuncture. 2003. N 6. P.5-18.

16.Nacatani Y., Vamashyta K. Ryodoraky Accupuncture. Tokyo: Nippon, 1977. 144 p.

17.Nakatani Y.A Guide for Application of Ryodoraku Autonomous Nerve Regulatory Therapy. Alhambra, Spain: Chan's Books and Products; 1972.260 p.

18.Nakatani Y. Skin electric resistance and Ryodoraku. Journal of Autonomic Nerve. 1956. N.6. P.160-184.

19. Roberts D. N., Shealy, C.N., Tiller W.A. Are there electrical devices that can measure the body's energy state change to an acupuncture treatment? Part 1. Meridian Stress Assessment MSA-21J. URL: http://journals.sfu.ca/seemj/index.php/seemj/ article/view/351/313. (дата звернення: 02.10.2012 p.)

20.Schorrenderger C.C. Therapie mit Akupunktur. Stuttgart: Hippokrates Verlag, 1984. Bd.1. $352 \mathrm{~s}$

21.Shcherbaty 1.A, Korkushko O.O. The use of reflexotherapy in the initial forms of cerebrovascular insufficiency in persons who suffered as a consequence of the accident at the Chernobyl Atomic Electric Power Station. Lik. Sprava. 1999. № 3. P.151-155.

22.Wang G.-J., Ayati M.H., Zhang W.-B. Meridian studies in China: a systematic review. JAMS Journal of Acupuncture and Meridian Studies. 2010. V.3, №.1. P.1-9.

23.Wang C.N., Weng C.S., Hu W.C., Chang Y.H., Lin J.G. The development of new Ryodoraku neurometric patterns. Journal of Medical and Biological Engineering. 2002. № 22. P.99-106.

24.Will Chen C., Chen-Jei Tai, Cheuk-Sing Choy e.a. Wave-Induced Flow in Meridians Demonstrated Using Photoluminescent Bioceramic Material on Acupuncture Points Evid Based Complement Alternat Med. 2013. URL: https://www.ncbi.nlm.nih. gov/pmc/articles/PMC3838801 (дата звернення: 02.10.2012 p.)

25. Yang W.S. Investigation of the lower resistance meridian IV. Speculation on the Physiological Functions of Acpuncture. Meridians Acta scieentarium naturalium Unviersitati Pekinensis. 2008. V.44, № 2. P.145-158.

26.Yeh M.L., Chen H.H., Lin I.H. Contemporary Meridians and Acupoints in Practice. Taipei, Taiwan: Farseeing publications, 2004. 120 p.

1. Vishnu-devananda, S. (1990). Polnaya illustrirovannaya kniga yogi [The Complete Yoga Illustrated Book]. Paritet-IN Folio. [in Russian].

2. Dzhafarov, M.A. (1968). Anatomicheskive i topograficheskive izmeneniva v nekotorykh vnutrennikh organakh pri fizicheskikh uprazhneniach [Anatomical and topographic changes in some internal organs during exercise] [Extended abstract of Doctoral dissertation]. Moscow. [in Russian].

3. Indikator energii tcheloveka [Human energy indicator] Catalog of radio amateur circuits $R L$ 2-2000. http://www.irls.narod.ru/ $\mathrm{rlbt} / \mathrm{med} / \mathrm{med02.htm} \mathrm{[in} \mathrm{Russian].}$

4. Krapivina, E.A. (1991). Fizicheskije uprazhnenija yogov [Physical exercises of yogis]. Znanie. [in Russian].

5. Krapivina, K.O, \& Musiyenko, O.V. (2006). Netradycijny pidhid do tradycijnoji fizychnoi kultury [Non-traditional approach to traditional physical culture]. LNU. [in Ukrainian].

6. Macheret, E.L, Samosyuk, I.Z. (1982). Rukovodstvo po refleksoterapii [Reflexology manual]. Vyschaya Schkola. [in Russian].

7. Merson, M.A. (1985). Sistema Riodoraku kak subjektivnyj kriterij ocenki efektivnosti lechenija refleksoterapijej [Ryodoraky system as a subjective criterion for evaluating the effectiveness of acupuncture treatment]. Abstracts report 2 Rep. conf. young medical scientists (pp.129-130). Riga. [in Russian].

8. Tabeeva, D.M. (1982). Rukovodstvo po iglorefleksoterapii [Guide to acupuncture]. Meditsyna. [in Russian].

9. Buts'ka, L.V. (2006). Analysis of obtained data after electropuncture diagnostics in sportsmen with different professional qualification. Lik. Sprava, 5-6, 43-49.

10.Fribus, A.G. (1999). Electrophysiological studies by the method of measuring the transcutaneous electrical current with Nakatani tables in healthy men exposed in a thermal chamber. Vopr. Kurortol. Fizioter. Lech. Fiz. Kult, 5, 24-26.

11.Goldura, N. (2010) Incursion into bioelectromagnetism. Rev. Med. Chir. Soc. Med. Nat. Iasi, 114 (1), 266-270.

12.Hyodo, M.D. (1975). Ryodoraku treathment and objective approach to acupuncture. Osaka.

13.Huang, S.-M., Chien, L.-Y., Chang, C.-C., Chen, P.-H., Tai, C.J. (2011). Abnormal gastroscopy findings were related to lower meridian energy. Evidence-based Complementary and Alternative Medicine. https://downloads.hindawi.com/journals/ ecam/2011/878391.pdf

14.Korkushko, A.O, Lyshnevski1 S.A. (2001). Computerized acupuncture methods in the diagnosis of autonomic nervous system disturbances. Lik. Sprava, 5-6, 117-119.

15.Liu, C.Z, \& Chang, Y.H. (2003). Channel medicine and meridian doctrine. Journal of Chinese Medical Association of Acupuncture, 6, 5-18.

16.Nacatani, Y, Vamashyta, K. (1977). Ryodoraky Accupuncture. Nippon.

17.Nakatani, Y. (1972). A Guide for Application of Ryodoraku Autonomous Nerve Regulatory Therapy. Chan's Books and Products.

18.Nakatani, Y. (1956). Skin electric resistance and Ryodoraku. Journal of Autonomic Nerve, 6, 160-184.

19.Roberts, D.N., Shealy, C.N., \& Tiller, W.A. Are there electrical devices that can measure the body's energy state change to 
an acupuncture treatment? Part 1, Meridian Stress Assessment (MSA-21J) http://journals.sfu.ca/seemj/index.php/seemj/article/ view/351/313.

20.Schorrenderger, C.C. (1984). Therapie mit Akupunktur. Hippokrates Verlag.

21.Shcherbaty1, A.A., Korkushko O.O. (1999). The use of reflexotherapy in the initial forms of cerebrovascular insufficiency in persons who suffered as a consequence of the accident at the Chernobyl Atomic Electric Power Station. Lik. Sprava, 3 , $151-155$

22.Wang, G.-J., Ayati, M.H., Zhang W.-B. (2010). Meridian studies in China: a systematic review. JAMS Journal of Acupuncture and Meridian Studies, 3 (1). 1-9.

23.Wang, C.N., Weng, C.S., Hu, W.C., Chang, Y.H., Lin, J.G. (2002). The development of new Ryodoraku neurometric patterns. Journal of Medical and Biological Engineering, 22, 99-106.

24. Will Chen, C, Chen-Jei Tai, Cheuk-Sing Choy (2013). Wave-Induced Flow in Meridians Demonstrated Using Photoluminescent Bioceramic Material on Acupuncture Points. Evid Based Complement Alternat Med. https://www.ncbi.nlm.nih.gov/pmc/ articles/PMC3838801/

25.Yang, W.S. (2008). Investigation of the lower resistance meridian IV. Speculation on the Physiological Functions of Acpuncture Meridians. Acta scieentarium naturalium Unviersitati Pekinensis, 44 (2), 145-158.

26. Yeh, M.L, Chen H.H, Lin I.H. (2004). Contemporary Meridians and Acupoints in Practice. Farseeing publications.

Стаття надійшла до редакції 15.10 .2021 р. Стаття прийнята до друку 20.10.2021 p.

\author{
Musiyenko Olena \\ Candidate of Biological Sciences, Associate Professor \\ Department of Physical Education, Sports and Health \\ Stepan Gzhtskyi National University of Veterinary Medicine and Biotechnologies Lviv, Ukraine
}

Chopyk Roman

Candidate of Pedagogical Sciences, Associate Professor

Department of Theory and Methods of Physical Education

Ivan Franko Drohobych State Pedagogical University, Drohobych, Ukraine

Kizlo Nataliya

Associate Professor

Department of Sports Disciplines and Methods of TeachingIvan Franko Drohobych State Pedagogical University, Drohobych, Ukraine

\title{
DETERMINATION OF THE ACTIVITY OF REFLEXOGENIC ZONES OF THE BODY DURING THE PERFORMANCE OF STATIC EXERCISE OF HATHA YOGA (DHANURASANA)
}

Abstract. By measuring the electrical conductivity of different meridians of the human body data can be obtained to demonstrate the meridian energies. Such non-invasive methods are used to stimulate acupuncture points on the meridians. There is a need to confirm the effectiveness of mechanisms of acupuncture for the human body using scientific methods. Measuring the electrical conductivity of different meridians provides indicators for interpretation. The aim of our study is to establish the possibility of using the method of studying the effect of exercise on the body by means of acupuncture diagnostics according to J.Nakatani's method on the example of static exercise, which is performed similarly to Dhanurasana (outside the bow in Hatha Yoga). Ten female students were examined. Measurements were taken before the exercise, during and after the exercise after 6 minutes. The results of the research showed significant changes in the indicators of electrical activity in the representative points of the meridians of the body. An increase in electrical activity in the meridians of the human body, which are responsible for the functions of the respiratory, cardiovascular systems, kidneys and adrenal glands, gallbladder, small and large intestines, spleen, pancreas, liver and bladder, and its decrease in the meridian of the stomach. The method of acupuncture diagnostics chosen allows determining the electrical activity of the meridians of the human body during static exercise. It is possible to offer use of this technique of research of influence of physical exercises on a human body along with other generally accepted scientific methods.

Key words: physical education; static exercise; acupuncture diagnostics methods. 